\title{
ASSESSMENT OF DELIVERY PATTERN AND FACTORS INFLUENCING THE PLACE OF DELIVERY AMONG WOMEN IN EAST KHASI HILLS DISTRICT OF MEGHALAYA.
}

Himashree Bhattacharyya, Star Pala.

1. Senior Resident Doctor, Department of Community Medicine, NEIGRIHMS, Shillong, Meghalaya.

2. Assistant Professor \& I/ c, Department of Community Medicine, NEIGRIHMS, Shillong, Meghalaya.

\section{CORRESPONDING AUTHOR}

Dr. Himashree Bhattacharyya,

Department of Community Medicine,

NEIGRIHMS, Mawdiangdiang, Shillong,

Meghalaya- 793018.

E-mail: bhimashre@yahoo.co.in,

Ph: 919436985886.

ABSTRACT: BACKGROUND: Maternal health reflects major part of the health status of a particular region, state, country and the whole nation. Each year approximately 8 million women suffer from pregnancy related complications and over half a million women die of these complications. Despite so many efforts, institutional deliveries account only $40.8 \%$ of the total deliveries in India and only 24.4\% in Meghalaya. Reproductive and health care services often fail to reach those most in need due to several reasons. AIM OF THE STUDY: 1.To assess the delivery pattern among women residing in the East Khasi Hills district of Meghalaya. 2. To study the factors influencing the place of delivery. SETTINGS AND DESIGN: Community based cross sectional study conducted in two urban and two rural areas in East Khasi Hills district of Meghalaya. MATERIALS AND METHODS: The household was taken as the sampling unit. The households were selected using simple random sampling. In the selected household all the females available who have given birth to a child in the last three years were interviewed using a pre tested Proforma. STATISTICAL ANALYSIS: Descriptive analysis and tests of statistical Inference (Chi Square test) was done. RESULTS \& OBSERVATION: A total of 340 women were interviewed. Majority of women 156 (45.9\%) were in the age group of 25-35 years. The total number of institutional deliveries was 218 (64.1\%) and home deliveries were 122 (35.8\%). Out of the total deliveries, $92(27.05 \%)$ of deliveries were conducted by untrained personnel and the rest $248(72.9 \%)$ were conducted by trained persons. Some of the socio demographic factors which were observed to be associated with the place of delivery are the age of the women, educational status of both the women and her husband, per capita family income, parity of women and the area of residence. CONCLUSION: Increasing the proportion of safe and institutional deliveries not only require better health care services but also attention should be given to people's educational level, socio economic status, general awareness as well as proper accessibility to the health care services.

KEY WORDS: Maternal, Delivery, Institutional, household, parity.

INTRODUCTION: Maternal health refers to the health of women during pregnancy, childbirth and the postpartum period. While motherhood is often a positive and fulfilling experience, for too many women it is associated with suffering, ill-health and even death. The major direct 
causes of maternal morbidity and mortality include hemorrhage, infection, high blood pressure, unsafe abortion, and obstructed labor. ${ }^{1}$

Maternal health reflects major part of the health status of a particular region, state and the whole nation. Abnormal changes during pregnancy, events at the time and the outcome of the delivery is of major essence in deciding the future of the child. The vision of the World Health Organization (WHO) in 'Making Pregnancy Safer' is 'a world in which skilled care at every birth is ensured for all women'. ${ }^{2}$

Despite several decades of global health initiative focused on maternal health, maternal mortality has proven to be an intractable problem. The Millennium Development Goal Indicator of maternal health, the maternal mortality ratio has remained unchanged over the past 15 years, with an estimated mean annual decline of $0.4 \%$ since 1990 -far short of the progress required to meet the Millennium Development Goal target of $75 \%$ reduction by $2015 .{ }^{3}$

Each year approximately 8 million women suffer from pregnancy related complications and over half a million women die of these complications. Of all maternal deaths that occur in developing countries, Africa and Asia have a lion's share of over $90 \% .{ }^{4}$ For every women who dies during pregnancy, approximately 30 more women suffer from injuries, infections and disabilities during pregnancy or child birth accounting at least 15 million women a year. ${ }^{2}$

In India, among the National Socio Demographic Goals for 2010, certain goals are directed towards safe delivery viz. to achieve $80 \%$ institutional deliveries and $100 \%$ deliveries by trained personnel by $2010 .{ }^{5}$ To promote institutional deliveries, provision has been made under the current Reproductive and Child Health (RCH) programme to encourage round the clock delivery services at PHC's and CHC's, strengthened supply of drugs, skilled man power on contractual basis and transport facilities to assist women in need. ${ }^{6} \mathrm{But}$ despite so many efforts, institutional deliveries account only $40.8 \%$ of the total deliveries in India and only $24.4 \%$ in Meghalaya. ${ }^{7,8}$ Reproductive health and basic health infrastructure and services often do not reach the remote areas and thus vast numbers of people cannot avail these services .Keeping in view all these factors the present study was conducted with the objective of assessing the delivery pattern and factors influencing the place of delivery in selected Areas of East Khasi Hills district of Meghalaya.

\section{AIM OF THE STUDY:}

1. To assess the delivery pattern among women residing in selected areas of East Khasi Hills, district of Meghalaya.

2. To study the factors influencing the place of delivery.

METHODS AND MATERIALS: A Community based Cross Sectional study was conducted in the two urban and two rural areas of East Khasi Hills district of Shillong. These areas were selected as they were the field practice areas of Community Medicine Department of NEIGRIHMS. The urban areas selected were Mawpat and Pynthorbah under Mawpat and Pynthorbah Urban Health Centre. The rural areas selected were Tynring A and Syeiong under Diengpasoh Primary Health Center.

The sample size was calculated by the formula 4PQ/ $\mathrm{L}^{2}$, where $\mathrm{P}=24.4 \%$ ( Positive character), $\mathrm{Q}=1-\mathrm{P}, \mathrm{L}=$ Allowable error. Considering the percentage of institutional deliveries in Meghalaya as $24.4 \%$ from the NFHS III data (2005-2006) and taking $20 \%$ as allowable error the sample size was calculated to be 310 . We however interviewed a total of 340 individuals in the study.

Journal of Evolution of Medical and Dental Sciences/Volume1/ Issue4/October-2012 Page 392 
In the respective areas, the household was the sampling unit. The number of individuals selected from each area was determined by proportionate allocation. In the respective areas the households were selected using simple random sampling after obtaining a list of all the households in the respective area from the ANM. In the selected household all the females available who have given birth to a child in the last three years were interviewed. Data was collected on socio demographic characteristics of the women and reasons for selecting their place of delivery. If no female was present in the selected house at the time of visit, then next house was taken into consideration till the required sample size is fulfilled. If a women had delivered more than once in the last 3 years, then information regarding only the last delivery was obtained to eliminate recall bias. The respondents were informed about the purpose of the study. They were assured about confidentiality. A pre-tested questionnaire was used and the questions asked were in the local language about their demographic data, delivery practices and the associated factors. The $\mathrm{p}$ value of $<.05$ was considered significant. Data analysis was done by descriptive analysis and analytical statistics by Chi Square test using SPSS version 17.0.

RESULTS AND OBSERVATION:A total of 340 women were interviewed .Out of these women $145(42.6 \%)$ women belonged to the age group 15-25 years, 156 (45.9\%) women belonged to the age group 25-35 years and 39 (11.5\%) women belonged to 35-45 years of age. With respect to the educational status $76(22.3 \%)$ women were found to be illiterate, $245(72.0 \%)$ women had done schooling and 19 (5.57\%) women had done post schooling. With respect to the educational status of the women's husbands 33 (9.7\%) were illiterate, 263 (77.4\%) of husbands had done schooling and $44(12.9 \%)$ had undergone post schooling. In this study, 95 (27.9\%) of women had per capita family income of less than Rs 750, 165 (48.5\%) of women had per capita income of Rs 750-1500, 62 (18.3\%) of women had per capita income of Rs 1500-3000 and $18(5.3 \%)$ of women had a per capita income of Rs 3000-6000.0ut of 340 women interviewed $179(52.6 \%)$ of women were from urban area and $161(47.4 \%)$ of women were from rural areas.

As per the type of delivery $300(88.2 \%)$ of women were found to have normal deliveries; $39(11.4 \%)$ of women had undergone Caesarean Section and only $1(0.2 \%)$ of women had forceps delivery.148 (43.5\%) women were nullipara and 192 (56.5\%) of women were found to be multipara. Out of 340 women studied $40(11.8 \%)$ had complications at the time of delivery whereas 300 (88.2\%) of them had no complications.

With regard to the place of delivery out of 340 women, 183 (53.9\%) of women delivered in a government hospital, 35 (10.3\%) of women delivered in a private hospital and 122 (35.8\%) of women delivered at home. Thus the number of institutional deliveries were 218(64.11\%) and home deliveries were 122 (35.88\%).Out of the total deliveries, 68 (20.0\%) of deliveries were conducted by Untrained Dais, 229 (67.4\%) of deliveries were done by either staff nurse or doctor, 19 (5.5\%) of deliveries were conducted by ANM and 24 (7.1\%) of deliveries were done by Others like mother or relative of the women.

The socio demographic variables taken into consideration which may influence the place of delivery are age group of the women, education of the women as well as her husband, per capita income, parity of the women, area of residence- rural or urban.

Age of women and place of delivery: In the present study, a significant association was observed between age group of the mother and place of delivery. [Table 1] 
Education and place of delivery: A significant association was also observed between mother's education and place of delivery [Table 2] A significant association was also observed between the husbands education level and place of delivery [Table3]

Income and place of delivery: Most of the mothers belonging to the lower income group had opted for home delivery. A significant association was observed between the per capita family income and the place of delivery [Table4]

Parity and place of delivery: A significant association was also found between parity and home delivery with most of the multi para women going for home delivery [Table5]

Residential area and place of delivery: 22 (18.1\%) of women from urban areas delivered at home in comparison to $100(81.9 \%)$ of women from rural areas. A significant association was observed between the area of residence classified into rural and urban and choice of place of delivery. [Table6]

In the present study a significant association was observed between the place of delivery and person conducting the delivery with most of the home deliveries being conducted by untrained persons. Almost all the hospital deliveries were conducted by trained nurses or doctors.[Table 7]

A significant association was observed between complications occurring at the time of delivery and place of delivery. [Table 8].The type of delivery and place are also associated with all the home deliveries being normal deliveries. [Table 9]

The primary reason given by the women for choosing home delivery were traditional attitude 38 (31.40\%), Lack of transport 33(27.28\%), less expenses 26 (21.48\%), familiar surroundings $16(12.39 \%)$, and $9(7.43 \%)$ gave no reasons.

The primary reason given by the women for choosing private hospitals as their place of delivery were better care 14 (40.00\%), more comfortable11 (31.42\%), less complications 7 $(20 \%)$ and $3(8.58 \%)$ women gave no reasons.

The primary reason given by the women for delivery in government hospitals are better care 66 (35.86\%), government initiatives 54 (29.35\%), comparatively less expenses 23(12.50\%), more doctors 19 (10.32\%) and no reason $21(11.95 \%)$.

DISCUSSION: The present study was conducted to assess the delivery pattern and factors influencing the place of delivery among women in East Khasi Hills district of Meghalaya. Majority of women 156 (45.9\%) were in the age group of 25-35 years and most of them $245(72.0 \%)$ had undergone schooling. The total number of institutional deliveries was 218 (64.11\%) and home deliveries were 122 (35.88\%). This is high compared to the figures of NFHS III where institutional deliveries were reported to be $40.8 \%$ in India and only $24.4 \%$ in Meghalaya. ${ }^{7}$ This may be due to the reason that the study was conducted in East Khasi Hills district of Meghalaya where access to health care services is better compared to the rest of the state. This can also be attributed to the increasing number of programs related to maternal and child health over time since the NFHS III data was of the year 2005-2006.

Some of the socio demographic factors which were observed to be associated with the place of delivery in our study are the age of the women, educational status of both the women and her husband, per capita income, parity of women and the area of residence.

A significant association was observed between the mother's age and place of delivery with more mother's in the younger age groups going for institutional deliveries. In a study conducted by Carol Wanjira on delivery practices and associated factors among mothers seeking child welfare services in Kenya it was observed that younger mothers were more likely 
to utilize skilled attendants during delivery than their elder counterparts. Mothers of the younger age groups are likely to be nullipara and may prefer institutional deliveries. Also the younger mothers may be more aware of the $\mathrm{MCH}$ services and benefits and therefore utilize the maternal health services better.

A significant association was also observed between mother's education and place of delivery. In the study conducted by Carol Wanjira on delivery practices among mothers in Kenya, a significant association was found between mother's education and place of delivery. ${ }^{9}$ Another study conducted by Sushma Kumari Saini et al in Chandigarh also shows that women with higher education level delivered in the institutes in significantly higher percentage than their counter parts ${ }^{10}$. In a study on maternal education and utilization of maternal and child health services in India using NFHS data by P. Govindasamy and B.M. Ramesh it was shown that education emerges as the single most important determinant of maternal health-care utilization in India when the influence of other intervening factors is controlled.11

A significant association was also observed between the husband's education and place of delivery. A study conducted by Joseph Bobby et al in Bangalore city also showed a significant relation between the father's education and place of delivery ${ }^{12}$. This can due to the reason that if the people are educated they have more awareness about the advantages and benefits of a hospital delivery and also of the complications arising out of a unsafe delivery. Therefore they are likely to opt for a safe institutional delivery.

Most of the mothers belonging to the lower income group had opted for home delivery. A significant association was observed between the family per capita income and the place of delivery. A study on Socioeconomic inequalities in use of delivery care services in India conducted by Abdul Salam and S. A. Siddiqui using NFHS II data also revealed that both economic and educational status of women are positively associated with use of maternal health care facilities ${ }^{13}$. Similarly the study by Joseph Bobby et al also showed that families with a low per capita income of less than Rs. 2,500/- preferred home deliveries ${ }^{12}$. A study conducted by Rajendra. R. Wagle in Nepal also showed that low socio-economic status has been found as a predictor for place of delivery ${ }^{14}$. Most of the research consistently shows that high cost is an important constraint to service utilization particularly for the poor .Delivery in private hospitals as well as government hospitals can lead to expenses with regard to travel as well as hospital stay, visits by family members etc which may be difficult in families of lower income group.

A significant association was also found between parity and home delivery with most of the multi para women going for home delivery. A study conducted by Reajendra R Wagle in Nepal also showed a significant association between home deliveries and multiparity ${ }^{14}$. The reason for this can be that the women and the family members are more apprehensive if the women is a nullipara and will take more precautions for safe delivery of the first born child.

It was seen that $22(18.1 \%)$ of women from urban areas delivered at home in comparison to 100 (81.9\%) of women from rural areas. The place of residence (Rural or Urban) also had a strong relation to the place of delivery. The study conducted by Rajendra R Wagle in Nepal showed that the distance to the maternity hospital as having a causal role for place of delivery. Long distance from the maternity hospital was found to be significantly associated with home delivery ${ }^{14}$.It was seen that women residing in rural areas had difficulty in hospital delivery due to lack of proper transport and other factors at the time. In a study by Amy J Kesterton regarding institutional delivery in rural India a strong association was observed between place of delivery and community access ${ }^{15}$. Hyam Bashour et al in a study on Syrian Women's preferences for birth place observed that the woman's area of residence was 
statistically related to women's preference for a doctor's attendance at birth versus a midwife's attendance ${ }^{16}$. Thus, distance to the health facility can be a major barrier in health care utilization.

A marginally significant association was observed between complications occurring at the time of delivery and place of delivery. This is because hospital deliveries are conducted by trained persons and better equipped, so the chances of any complications occurring are lesser compared to home deliveries.

Out of 122 home deliveries, $55.8 \%$ were done by untrained dais, $24.5 \%$ were done by trained persons (ANM/doctor) and $19.7 \%$ were done by others. In a study on socio demographic correlates of place and person conducting the delivery in a rural community of Andhra Pradesh it was observed that untrained dais, trained dais and others conducted home deliveries in $43.5 \%, 40.3 \%$ and $16.2 \%$ of cases respectively. ${ }^{17}$ The place of delivery also had a strong relation to the person conducting the delivery and the type of delivery. This was obvious as deliveries in hospital are always conducted by trained nurses or doctors and have the back up to conduct all deliveries whether Normal or CS in contrast to home deliveries which are always normal deliveries and mostly conducted by untrained personnel.

The major reason given by people for home deliveries is traditional attitude, Lack of transport, less expenses and familiar surroundings. The major reason for institutional deliveries was better care and government initiatives.

From our study it has been observed that Increasing the proportion of safe and institutional deliveries not only require better health care services but also attention should be given to people's educational level, socio economic status , general perception, as well as proper accessibility to the health care services. Therefore appropriate steps should be taken for upliftment of the educational and socio economic status, better access to health care and changing the traditional attitude towards the deliveries.

Table 1: Distribution of place of delivery in relation to age of the women

\begin{tabular}{|l|l|l|l|}
\hline \multirow{2}{*}{ Age } & Home & Institutional & Total \\
\cline { 2 - 4 } & No (\%) & No (\%) & No (\%) \\
\hline $15-25$ & $55(45.1 \%)$ & $90(41.3 \%)$ & $145(42.6 \%)$ \\
\hline $25-35$ & $46(37.7 \%)$ & $110(50.4 \%)$ & $156(45.9 \%)$ \\
\hline $35-45$ & $21(17.2 \%)$ & $18(8.3 \%)$ & $39(11.5 \%)$ \\
\hline Total & $\begin{array}{l}122 \\
(100.0 \%)\end{array}$ & $218(100.0 \%))$ & $340(100.0 \%)$ \\
\hline
\end{tabular}

(Chi Sq=8.508 at $\mathrm{p}<.05$,d.f $=2$, Table value $=5.99$ )

Table 2: Distribution of place of delivery in relation to educational status of women

\begin{tabular}{|l|l|l|l|}
\hline \multirow{2}{*}{$\begin{array}{l}\text { Education } \\
\text { status }\end{array}$} & Home & Institutional & Total \\
\cline { 2 - 4 } & No (\%) & Number (\%) & No (\%) \\
\hline Illiterate & $56(45.92)$ & $20(9.2 \%)$ & $76(22.3)$ \\
\hline School & $65(53.27 \%)$ & $180(82.6 \%)$ & $245(72.0)$ \\
\hline Post School & $1(0.81 \%)$ & $18(8.2 \%)$ & $19(5.57)$ \\
\hline & $122(100.0 \%)$ & $218(100.0 \%)$ & $340(100.0 \%)$ \\
\hline
\end{tabular}


(Chi Sq=64.8 at $\mathrm{p}<.05$,d.f. $=2$, Table value=5.99)

** Post School refers to HS, graduation, post graduation, any degree course undertaken after completing school.

Table 3: Distribution of place of delivery in relation to educational status of women's husbands

\begin{tabular}{|l|l|l|l|}
\hline Education status & Home & Institutional & Total \\
\cline { 2 - 4 } & No (\%) & No(\%) & No (\%) \\
\hline Illiterate & $17(13.9 \%)$ & $16(7.3 \%)$ & $33(9.7 \%)$ \\
\hline School & $101(82.8 \%)$ & $162(74.4 \%)$ & $263(77.4 \%)$ \\
\hline Post School & $4(3.3 \%)$ & $40(18.3 \%)$ & $44(12.9 \%)$ \\
\hline & $122(100.0 \%)$ & $218(100.0 \%)$ & $340(100.0 \%)$ \\
\hline
\end{tabular}

(Chi Sq=17.959 at $\mathrm{p}<.05$, d.f. $=2$ Table value $=5.99$ )

Table4: Distribution of place of delivery in relation to the per capita family income

\begin{tabular}{|l|l|l|l|}
\hline \multirow{2}{*}{$\begin{array}{l}\text { Per capita family } \\
\text { Income }\end{array}$} & Home & Institutional & Total \\
\cline { 2 - 4 } & No (\%) & No (\%) & No (\%) \\
\hline$<750$ & $72(59.1 \%)$ & $23(10.5 \%)$ & $95(27.9 \%)$ \\
\hline $750-1500$ & $39(31.9 \%)$ & $126(57.8 \%)$ & $165(48.5 \%)$ \\
\hline $1500-3000$ & $9(7.4 \%)$ & $53(24.4 \%)$ & $62(18.3)$ \\
\hline Total & $2(1.6 \%)$ & $16(7.3 \%)$ & $18(5.3 \%)$ \\
\hline
\end{tabular}

(Chi Sq=94.42 at $\mathrm{p}<.05$, d.f. $=3$, Table value $=7.81$ )

Table 5: Distribution of place of delivery in relation to parity of women

\begin{tabular}{|l|l|l|l|}
\hline \multirow{2}{*}{ Parity } & Home & Institutional & Total \\
\cline { 2 - 4 } & No (\%) & No (\%) & No (\%) \\
\hline Nullipara & $38(31.2 \%)$ & $110(50.4 \%)$ & $148(43.5 \%)$ \\
\hline Multipara & $84(68.8 \%)$ & $108(49.6 \%)$ & $192(56.5 \%)$ \\
\hline Total & $122(100.0 \%)$ & $218(100.0 \%)$ & $340(100.0 \%)$ \\
\hline
\end{tabular}

(Chi Sq=11.51 at $\mathrm{p}<.05$, d.f. $=1$, Table value $=3.84$ )

Table6: Distribution of place of delivery in relation to the place of residence of women

\begin{tabular}{|l|l|l|l|}
\hline \multirow{2}{*}{ Area } & Home & Institutional & Total \\
\cline { 2 - 4 } & No (\%) & No (\%) & No (\%) \\
\hline Urban & $22(18.1 \%)$ & $157(72.1 \%)$ & $179(52.6 \%)$ \\
\hline Rural & $100(81.9 \%)$ & $61(27.9 \%)$ & $161(47.4 \%)$ \\
\hline Total & $122(100.0 \%)$ & $218(100.0 \%)$ & $340(100.0 \%)$ \\
\hline
\end{tabular}

(Chi Sq=90.42, d.f.=1, Table value=3.84) 
Table7: Distribution of place of delivery with respect to person conducting delivery

\begin{tabular}{|l|l|l|l|}
\hline \multirow{2}{*}{ Person } & Home & Institutional & Total \\
\cline { 2 - 4 } & No (\%) & No (\%) & No (\%) \\
\hline Un Trained Dai & $68(56.1 \%)$ & $0(0 \%)$ & $68(20.0 \%)$ \\
\hline Nurse/Doctor & $11(9.1 \%)$ & $218(100.0 \%)$ & $229(67.4 \%)$ \\
\hline Trained dai/ANM & $19(15.7 \%)$ & $0(0 \%)$ & $19(5.5 \%)$ \\
\hline Others & $24(19.1 \%)$ & $0(0 \%)$ & $24(7.1 \%)$ \\
\hline Total & $122(100.0 \%)$ & $218(100.0 \%)$ & $340(100.0 \%)$ \\
\hline
\end{tabular}

(Chi Sq=286.29 at $\mathrm{p}<.05$, d.f. $=3$, Table value $=7.81$ )

Table8: Distribution of place of delivery in relation to complications at the time of delivery

\begin{tabular}{|l|l|l|l|}
\hline \multirow{2}{*}{ Complications } & Home & Institutional & Total \\
\cline { 2 - 4 } & No (\%) & No (\%) & No (\%) \\
\hline Present & $20(16.4 \%)$ & $20(9.2 \%)$ & $40(11.8 \%)$ \\
\hline Absent & $102(83.6 \%)$ & $198(90.8 \%)$ & $300(88.2 \%)$ \\
\hline Total & $122(100.0 \%)$ & $218(100.0 \%)$ & $340(100.0 \%)$ \\
\hline
\end{tabular}

(Chi Sq=3.92 at $\mathrm{p}<.05$, d.f. $=1$, Table value $=3.84$

Table9: Distribution of place of delivery in relation to the type of delivery

\begin{tabular}{|l|l|l|l|}
\hline \multirow{2}{*}{ Type } & Home & Institutional & Total \\
\cline { 2 - 4 } & No (\%) & No (\%) & No (\%) \\
\hline Normal & $122(100.0 \%)$ & $178(81.6 \%)$ & $300(88.2 \%)$ \\
\hline CS & $0(0 \%)$ & $39(18.0 \%)$ & $39(11.4 \%)$ \\
\hline Forceps & $0(0 \%)$ & $1(0.4 \%)$ & $1(0.2 \%)$ \\
\hline Total & $122(100.0 \%)$ & $218(100.0 \%)$ & $340(100.0 \%)$ \\
\hline
\end{tabular}

(Chi Sq $=25.22$ at $\mathrm{p}<.05$, d.f. $=2$, Table value $=5.99$ )

\section{REFERENCES:}

1. World Health Organization-Maternal Health. Available at www.who.int/topics/maternal health/en/

2. Garg Rajesh; Shyamsunder Deepti ; Singh Tejbir, Padda Avtar Singh -A study on delivery practices among women in rural Punjab. Health and Population: Perspectives and Issues. Vol.33(1); 23-33;2010

3. Kruk ME, Paczkowski M, Mbaruku G, de Pinho H, Galea S.Women's Preferences for Place of Delivery in Rural Tanzania: A Population- based Discrete Choice Experiment; Am I Public Health. 2009 Sep; 99(9):1666-72. Epub 2009 Jul .

4. UNICEF(2006). A call for quality.In: The State of the World's Children 2007: Women \& Children- The double dividend of gender equality. The United Nations Children's Fund (UNICEF),26,127,p5\ 
5. National Commission on Population (GoI); National Population Policy 2000 Available at population commission.nic.in/npp-obj.htm.

6. RCH II; Programme Objectives and Strategies. Available at www.nohfw.nic.in/NRHM/PIP-69-10/ Rajasthan/RCH \%20-text.pdf

7. National Family Health Survey-III; Key Indicators for India. Available at www.chsj.org/uploads/1/0/2/1/10215849/india.pdf

8. DLHS-MoH \& FW; GoI; DLHS-3 (2007-2008). Available at www.jsk.gov.in/dlhs3/Meghalaya.pdf

9. Carol Wanjira, Moses Mwangi, Evans Mathenge, Gabriel Mbugua and Zipporah Ng'ang'a. Delivery Practices and Associated Factors among Mothers Seeking Child Welfare Services in Selected Health Facilities in Nyandarua South District, Kenya .BMC Public Health 2011, 11:360 doi:10.1186/1471-2458-11-360. Available at http://www.biomedcentral.com/1471-2458/11/360.

10. Saini Kumari Sushma, Walia Indrajit. Trends in place of delivery among low income community in a resettled colony of Chandigarh, India. Nursing and Midwifery Research Journal, Vol 5, No 4, Oct 2009. Available at www. medind.nic.in/nad/t09/i4/nadt09i4p1333.pdf

11. Pavalavalli Govindasamy, Ramesh B.M.; Maternal education and utilization of maternal and child health services in India. NFHS subject reports No 5; Dec,1997; International Institute for Population Sciences; Mumbai; India.

12. Bobby Joseph, S.R. Sri Krishna, Jisha Philip and Belinda George. Preferences for home deliveries in a suburban community of bangalore city. Health and Population. Perspectives and Issues 25 (2): 96 - 103, 2002. Available at www.medind.nic.in/hab/t02/12/habt02i2p96.pdf

13. Abdul Salam, S A Siddiqui. Socioeconomic inequalities in use of delivery care services in India. J Obstet Gynecol India Vol. 56, No. 2 : March/April 2006 ,Pg 123-127

14. Rajendra R Wagle, Svend Sabroe and Birgitte B Nielsen. Socioeconomic and physical distance to the maternity hospital as predictors for place of delivery: an observation study from Nepal .BMC Pregnancy and Childbirth 2004, 4:8 doi:10.1186/1471-2393-4-8. Available at http://www.biomedcentral.com/1471-2393/4/8

15. Amy J Kesterton*, John Cleland, Andy Sloggett and Carine Ronsmans. Institutional delivery in rural India: the relative importance of accessibility and economic status BMC Pregnancy and Childbirth 2010, 10:30 Available at :http://www.biomedcentral.com/1471-2393/10/30

16. Hyam Bashour et al, Syrian Women's Preferences for Bitrth Attendant and Birth place . PMC- Pub Med Central 2005; March; 32 (1): 20-26. Available at www.nebi.nlm.gov/pmc/articles/PMC 1457105/

17. K. Raghava Prasad, K. Nagaraj; Socio Demographic Correlates of Place of Delivery and person conducting the delivery in a rural community in Andhra Pradesh. J. Human Ecolo; 12(5): 357-362 (2001) 